\title{
PRODUÇÃO E CARACTERIZAÇÃO DE ESPUMAS CERÂMICAS OBTIDAS A PARTIR DE LODO DE ANODIZAÇÃO DE ALUMÍNIO
}

Graziela Guzi de Moraes, João Batista Rodrigues Neto, Dachamir Hotza* e Antonio Pedro Novaes de Oliveira

Departamentos de Engenharia Mecânica e Engenharia Química, Universidade Federal de Santa Catarina, 88040-900 Florianópolis - SC, Brasil

Bianca Goulart de Oliveira e Therezinha Maria Novais de Oliveira

Departamento de Engenharia Ambiental, Universidade da Região de Joinville, 89219-905 Joinville - SC, Brasil

Recebido em 23/3/11; aceito em 29/6/11; publicado na web em 5/8/11

\begin{abstract}
PRODUCTION AND CHARACTERIZATION OF CERAMIC FOAMS OBTAINED FROM Al-ANODIZING SLUDGE. Ceramic foams were produced from a sludge generated in the aluminum anodizing process by using an industrial polyurethane foam (replication method) with open cell sizes of $10 \pm 5$ ppi (porosity $=97 \%$ ) which were impregnated with suspensions containing 50$61 \mathrm{wt} . \%$ alumina, $1 \mathrm{wt} . \%$ citric acid, $6 \mathrm{wt} . \%$ bentonite and fired at $1600{ }^{\circ} \mathrm{C}$ for $2 \mathrm{~h}$. The aluminum anodizing sludge shows a high alumina content $(87.5 \mathrm{wt} . \%)$ and a low particle size $(\sim 1.7 \mu \mathrm{m})$ after calcination and milling. The obtained filters show porosity of approximately $70 \%$, filtration capability (mass water flow) of $1.7 \mathrm{~kg} / \mathrm{s}$ and mechanical strength under compression of $2.40 \mathrm{MPa}$.
\end{abstract}

Keywords: wastes; alumina; ceramic foams.

\section{INTRODUÇÃO}

As indústrias de produção e transformação de materiais geram, em maior ou menor grau, resíduos, os quais nem sempre têm uma disposição ecologicamente adequada ou uma destinação de utilização. Em alguns casos, entretanto, esses produtos secundários podem ser diretamente reutilizados como matérias-primas em outros processos industriais. Como tais, eles perdem seus rótulos de poluentes e encontram novas aplicações com elevado valor agregado e consequente benefício para a sociedade e proteção do ambiente. ${ }^{1,2}$

$\mathrm{O}$ desenvolvimento de práticas de reciclagem tem se tornado expressivo em todo o mundo nos últimos anos. Em países como o Brasil, existem muitos resíduos industriais com potencial de utilização e que merecem investigação e estudo. Um desses resíduos é o lodo gerado no processo de anodização do alumínio.

A anodização do alumínio é um processo eletroquímico usado para produzir finas camadas de alumina $\left(\mathrm{Al}_{2} \mathrm{O}_{3}\right)$ sobre a superfície de componentes de alumínio. O tratamento confere aos componentes ou partes produzidas uma alta resistência à corrosão e à abrasão e possibilita efeitos estéticos, tais como a coloração com a manutenção dos padrões do projeto original. ${ }^{3}$ Este processo consome muita água e gera grandes quantidades de lodo ( 100.000 t/ano) nos países da União Europeia. ${ }^{4}$ No Brasil estima-se que para cada tonelada de material anodizado, $1 \mathrm{t}$ de lodo é gerada.

O lodo é constituído, majoritariamente, de hidróxido de alumínio coloidal, hidróxido de sódio ou cálcio (gerados a partir das soluções de neutralização), sulfatos de alumínio (usados como agentes floculantes) e água ( $85 \%)$. O lodo é frequentemente classificado como um material não tóxico, ${ }^{5}$ mas a sua disposição, considerando as quantidades produzidas, implica em elevada redução de volume (ex. filtro prensagem) e custos de transporte (22-30 US\$/t). ${ }^{4}$ Por outro lado, o elevado teor de alumina do lodo calcinado sugere um elevado potencial de reciclagem. Esse resíduo poderia, por exemplo, ser usado no processamento de materiais à base de alumina ou incorporado em outros produtos cerâmicos com propriedades tecnológicas de grande interesse, tais como isolamento elétrico, resistência mecânica

*e-mail:dhotza@gmail.com e refratariedade. ${ }^{6,7}$ Outras possíveis aplicações estão relacionadas à produção de fritas cerâmicas, engobes, esmaltes cerâmicos, pigmentos cerâmicos e cimentos, ${ }^{8-10}$ bem como filtros para fundição, com propriedades adequadas para a filtração/purificação e controle de fluxo de metais líquidos para a obtenção de peças ou componentes fundidos com melhores desempenhos.

Vários métodos vêm sendo empregados para fabricar cerâmicas celulares. ${ }^{11}$ Em particular, o método da réplica é um processo simples e de baixo custo, usado geralmente para a produção de filtros de fundição. O processo consiste basicamente na impregnação de uma espuma polimérica por uma suspensão de pó cerâmico ou vítreo, ${ }^{12}$ seguida de tratamento térmico, que inclui a degradação da parte orgânica e a sinterização (e eventual cristalização) do material inorgânico, resultando na réplica da espuma original.

Apesar da necessidade de calcinação do lodo para torná-lo uma matéria-prima adequada para ser utilizada na maioria das aplicações, essa iniciativa é válida. De fato, a produção de alumínio, a partir da bauxita, consome muita energia e a reciclagem do alumínio e de seus resíduos tem tornado o alumínio um metal acessível com preço relativamente constante no mercado já que a energia necessária para a sua reciclagem (refusão) corresponde a $\sim 5 \%$ do total da energia necessária para produzi-lo a partir da bauxita. De cada $5 \mathrm{t}$ de bauxita resultam, em média, $2 \mathrm{t}$ de alumina e $1 \mathrm{t}$ de alumínio.

Neste contexto, este trabalho apresenta resultados referentes à caracterização de um lodo gerado em processo industrial de anodização de alumínio e investiga a possibilidade de sua utilização como uma matéria-prima alternativa para a produção de filtros para fundição.

\section{PARTE EXPERIMENTAL}

Uma amostra de lodo (10 kg) de processo de anodização de alumínio foi inicialmente coletada em uma empresa localizada no estado de Santa Catarina sendo, em uma etapa posterior, tratada e caracterizada térmica e quimicamente. O lodo selecionado, como fornecido, apresentou um elevado teor de umidade ( $25 \%$ em massa). Por esta razão, o lodo úmido foi secado a $120{ }^{\circ} \mathrm{C}$ por $24 \mathrm{~h}$, com ventilação forçada em um secador de laboratório, e calcinado em um forno de laboratório a $1200{ }^{\circ} \mathrm{C}$ por $2 \mathrm{~h}$, a uma taxa de aquecimento 
de $10{ }^{\circ} \mathrm{C} / \mathrm{min}$ para decompor os hidróxidos e os principias sulfatos. Após tratamento térmico, a amostra foi esfriada no interior do forno. A alumina $\left(\mathrm{Al}_{2} \mathrm{O}_{3}\right)$ é a fase cristalina estável determinada através de difratometria de raios X (Modelo PW 1830, Philips) utilizando um tubo de cobre, radiação $(\mathrm{CuK} \alpha)$, potência de $40 \mathrm{kV}$ e corrente de 40 $\mathrm{mA}$ e intervalo de medida ( $2 \theta)$ entre 10 e $70^{\circ}$.

Após calcinação, amostras de alumina foram moídas e os tamanhos de partículas dos pós resultantes foram medidos por difração a laser (Cilas, 1064). Foram testados dois métodos de moagem. Inicialmente, foi feita moagem a úmido em moinho de bolas (Servitech, CT 242) por até $144 \mathrm{~h}$. Com o intuito de diminuir o tempo de moagem, foi utilizado também um moinho de alta energia do tipo planetário (Fritsch, Pulverisette 6). Nesse caso, a moagem foi realizada a seco com $50 \mathrm{~g}$ de sólidos e $50 \mathrm{~g}$ de bolas de ágata durante 20,25 e 30 min. A área de superfície específica foi medida por meio da técnica de BET (Micromeritics, ASAP 2010).

A composição química média do lodo, nos estados de fornecimento e após calcinação, foi obtida por meio de análises quantitativas por fluorescência de raios X (Philips, PW 2400). As reações físicas e químicas e as perdas de massa durante aquecimento de amostras de lodo foram avaliadas por análises térmica diferencial e termogravimétrica (ATD/TG) em ar seco (Netzsch, STA-409, ) a uma taxa de aquecimento de $10{ }^{\circ} \mathrm{C} / \mathrm{min}$ com amostras em pó de $20 \mathrm{mg} \mathrm{e} \mathrm{Al}_{2} \mathrm{O}_{3}$ como material de referência.

De maneira a obter espumas de $\mathrm{Al}_{2} \mathrm{O}_{3}$ por meio do processo da réplica polimérica, foram preparadas suspensões aquosas com diferentes concentrações de alumina calcinada (50, 54 e $58 \%$ em massa) e de água destilada (50, 46 e $42 \%$ em massa). Em todas as suspensões foram feitas adições de 2, 4, 6 e 10\% em massa de bentonita (ligante) e $0,5,1$ e $1,5 \%$ em massa de ácido cítrico (dispersante), respectivamente. As suspensões foram homogeneizadas em moinho de bolas de alumina por $15 \mathrm{~min}$. Subsequentemente, medidas de viscosidade foram realizadas em um viscosímetro dinâmico (Haake, Polylab System/52p Rheomex).

Como substratos (templates) para as suspensões foram usadas esponjas comerciais de poliuretano (Crest Foam Industries, EUA; INOAC Corporation, Japão) com distribuição monomodal de poros de $10 \pm 5$ poros por polegada (ppi, pores per inches). Amostras das esponjas de poliuretano (PU) adequadamente seccionadas foram, em uma etapa sucessiva, imersas nas suspensões preparadas. As amostras das esponjas impregnadas foram comprimidas para remoção do excesso de suspensão. Em uma etapa seguinte, as amostras foram secas a temperatura ambiente por $24 \mathrm{~h}$. Com a finalidade de se determinar o comportamento durante a sinterização, a suspensão resultante foi seca até um teor de umidade residual de 5,5\% e, então, granulada em um cilindro de plástico por $10 \mathrm{~min}$. A retração linear in situ de amostras compactadas (10 MPa) foi medida por meio de um dilatômetro ótico (Expert, Misura ODHT) a $10{ }^{\circ} \mathrm{C} / \mathrm{min}$ em ar.

$\mathrm{O}$ tratamento térmico das amostras impregnadas é um processo que compreende, normalmente, dois estágios e foi realizado em um forno elétrico em atmosfera de ar. O primeiro estágio, conduzido até $800{ }^{\circ} \mathrm{C} / 2 \mathrm{~h}$ com taxa de aquecimento de $1{ }^{\circ} \mathrm{C} / \mathrm{min}$, consiste de uma decomposição lenta e eliminação por queima da esponja de PU, mantendo a estrutura celular do pó de alumina. O segundo estágio, até $1600{ }^{\circ} \mathrm{C} / 2 \mathrm{~h}$ com taxa de aquecimento de $10^{\circ} \mathrm{C} / \mathrm{min}$, está relacionado à sinterização e densificação do pó de alumina. Esses intervalos de temperatura foram escolhidos, inicialmente, de acordo com os resultados das análises térmicas realizadas. Esponjas de PU e amostras tratadas termicamente foram seccionadas e preparadas para fotografias.

Com a finalidade de se avaliar a densidade e, assim, a porosidade das espumas cerâmicas produzidas e também dos filamentos ou arestas das estruturas celulares obtidas, foi calculada, inicialmente, a densidade geométrica, $\left(\rho_{\mathrm{g}}, \mathrm{g} / \mathrm{cm}^{3}\right)$, a partir de medidas de volume e de massa em compactos de pós (corpos-de-prova cilíndricos com dimensões nominais de $10 \mathrm{~mm}$ de diâmetro x $16 \mathrm{~mm}$ de altura) e em espumas cerâmicas (corpos-de-prova com dimensões nominais de 48 mm x 48 mm de lado x 24 mm de espessura já que uma retração linear de $21 \%$ é esperada e os filtros comerciais têm dimensões nominais de 40 x 40 × $20 \mathrm{~mm}$ ) impregnadas e sinterizadas.

Corpos-de-prova com dimensões nominais de 20 × 20 x $20 \mathrm{~mm}$ também foram preparados para ensaios de resistência mecânica. Em uma etapa posterior, a densidade teórica ou real $\left(\rho_{\mathrm{r}}, \mathrm{g} / \mathrm{cm}^{3}\right)$ foi medida por meio de picnometria a gás hélio (Quantachrome, Ultrapycnometer 1000). A partir dos resultados de densidade geométrica $\left(\rho_{\mathrm{g}}\right)$ e de densidade real $\left(\rho_{\mathrm{r}}\right)$, a porosidade $(\varepsilon)$ das amostras (espumas cerâmicas sinterizadas e compactos de pós) foi calculada por meio da Equação 1.

$$
\varepsilon=\left[1-\left(\rho_{\mathrm{g}} / \rho_{\mathrm{r}}\right)\right] \cdot 100
$$

A porosidade é um fator importante nos materiais celulares. As propriedades das estruturas tipo colmeia e tipo espuma dependem principalmente de suas porosidades. De fato, à medida que a porosidade das cerâmicas celulares diminui, a espessura das paredes das células aumenta. ${ }^{11}$ Dessa forma, foram calculados o percentual efetivo de sólidos (\% ES) retido nas espumas após a sinterização (Equação 2) e o percentual de sólidos sem os canais (\%SSC) que eram ocupados pelos filamentos da espuma de poliuretano (Equação 3), bem como a retração linear, RL (\%) por meio da Equação 4.

$$
\mathrm{ES}=\varepsilon_{1}-\varepsilon_{2}
$$

onde $\varepsilon_{1}$ é a porosidade (\%) da espuma de PU e $\varepsilon_{2}$ é a porosidade (\%) da espuma cerâmica sinterizada.

$$
\mathrm{SSC}=\mathrm{ES}-\mathrm{SPU}
$$

onde SPU é o percentual de sólido da espuma de PU.

$$
\mathrm{RL}=\left[\left(\mathrm{L}_{\mathrm{i}}-\mathrm{L}_{\mathrm{f}}\right) / \mathrm{L}_{\mathrm{i}}\right] \cdot 100
$$

onde $\mathrm{L}_{\mathrm{i}}$ é a medida da altura da amostra a verde $(\mathrm{mm})$ e $\mathrm{L}_{\mathrm{f}}$ é a medida da altura da amostra sinterizada ( $\mathrm{mm})$.

A resistência mecânica de corpos-de-prova sinterizados (30 unidades) foi medida por compressão. $\mathrm{O}$ equipamento utilizado foi uma máquina universal de ensaios mecânicos (Emic, DL 2000), com velocidade de carregamento de $1 \mathrm{~mm} / \mathrm{min}$. Através dos dados dos ensaios de resistência mecânica, foi feita uma estimativa das falhas em espumas sinterizadas através do módulo de Weibull, uma distribuição de probabilidade contínua, que também é utilizada para estimar o tempo de vida de equipamentos. A tensão característica $\sigma_{0}$, que indica o nível de tensão para o qual a probabilidade de sobrevivência dos corpos-de-prova é de $63,2 \%$ para qualquer tensão, e o módulo de Weibull $(\mathrm{m})$ foram estimados utilizando-se a Equação 5.

$$
\ln \left[1 /\left(1-\mathrm{F}_{v}\right)\right]=\left(\sigma / \sigma_{0}\right)^{m}
$$

onde $F_{v}$ é a probabilidade de falha, $\sigma$ é a tensão máxima (MPa), $\sigma_{0}$ é a tensão característica (MPa) e $m$ o módulo de Weibull, que é utilizado para descrever a dispersão relativa dos dados. A função da tensão característica $\left(\sigma_{0}\right)$ é comumente usada em dois parâmetros da distribuição Weibull e é descrita por meio da Equação 6.

$$
\sigma_{0}=\sigma /\left(K_{c} V\right)^{t / m}
$$

onde $V$ é o volume do filamento sob tensão $\left(\mathrm{mm}^{3}\right), K_{c}$ é uma constante 
relacionada à geometria de carregamento e $t$ é a espessura de aresta $(\mathrm{mm})$. A distribuição de Weibull é traçada em uma escala específica (gráfico de Weibull), no qual a função é representada por uma reta.

Foram realizados também ensaios de resistência ao choque térmico em água (NBR 13202), ${ }^{13} \mathrm{em}$ forno mufla (Jung, TB 3012) às temperaturas de 800,900 e $1000{ }^{\circ} \mathrm{C} / 30$ min ( 2 corpos-de-prova de espumas cerâmicas para cada temperatura).

Amostras das espumas cerâmicas produzidas foram embutidas em resina acrílica e, então, lixadas e polidas com pasta de alumina $(1 \mu \mathrm{m})$. Após polimento, as amostras foram recobertas com ouro para observações em microscópio eletrônico de varredura (MEV, Jeol, JSM-6390LV). A caracterização fluidodinâmica foi realizada calculando-se a vazão mássica $\left(Q_{m}\right)$ de água através das espumas sinterizadas por meio de medidas de massa de água $(\mathrm{kg})$ e tempo de escoamento (s), com o uso de um cronômetro.

\section{RESULTADOS E DISCUSSÃO}

A umidade do lodo como fornecido foi de aproximadamente $85 \%$ em massa, a qual foi parcialmente removida durante a secagem. A perda de massa durante calcinação foi de $\sim 24 \%$. A composição química média do lodo calcinado (Tabela 1) mostra que o mesmo contém basicamente $\mathrm{Al}_{2} \mathrm{O}_{3}(87,5 \%$ em massa) e pequenas quantidades de outros óxidos resultantes de contaminações e de aditivos químicos usados no tratamento da água.

As amostras de lodo foram calcinadas a diferentes temperaturas. No entanto, a cristalização da alumina ocorre a partir de $1200{ }^{\circ} \mathrm{C}$, razão pela qual esta foi a temperatura utilizada como uma referência para a calcinação desses lodos. O lodo como fornecido, Figura 1a, é praticamente amorfo já que nenhuma fase cristalina importante foi detectada. A Figura 1b refere-se ao lodo no estado calcinado, indicando a presença de alumina- $\alpha\left(\mathrm{Al}_{2} \mathrm{O}_{3}\right.$, ICSD 01-081-1667),

Tabela 1. Composição química do lodo de anodização de alumínio, como fornecido e calcinado, e de uma alumina comercial

\begin{tabular}{lccc}
\hline Óxidos & \multicolumn{3}{c}{ Composição química média (\% massa) } \\
\cline { 2 - 4 } & $\begin{array}{c}\text { Lodo como } \\
\text { fornecido }\end{array}$ & $\begin{array}{c}\text { Lodo } \\
\text { calcinado }\end{array}$ & $\begin{array}{c}\text { *Alumina } \\
\text { comercial }\end{array}$ \\
\hline $\mathrm{Al}_{2} \mathrm{O}_{3}$ & 55,5 & 87,5 & 99,7 \\
$\mathrm{SO}_{3}$ & 12,1 & 5,3 & \\
$\mathrm{Na}_{2} \mathrm{O}$ & 2,9 & 5,2 & 0,12 \\
$\mathrm{SiO}_{2}$ & 0,6 & 0,7 & 0,02 \\
$\mathrm{Fe}_{2} \mathrm{O}_{3}$ & 0,3 & 0,3 & 0,02 \\
$\mathrm{CaO}$ & 0,1 & 0,2 & \\
$\mathrm{Cl}$ & 0,1 & - & \\
$\mathrm{MgO}_{\mathrm{SnO}}$ & 0,1 & 0,2 & \\
$\mathrm{P}_{2} \mathrm{O}_{5}$ & $<0,1$ & $<0,1$ & \\
$\mathrm{NiO}$ & $<0,1$ & $<0,1$ & \\
$\mathrm{MnO}$ & $<0,1$ & $<0,1$ & \\
$\mathrm{~K}_{2} \mathrm{O}$ & $<0,1$ & $<0,1$ & \\
$\mathrm{ZnO}$ & $<0,1$ & 0,2 & \\
$\mathrm{SrO}$ & $<0,1$ & $<0,1$ & \\
$\mathrm{CuO}$ & - & $<0,1$ & \\
$\mathrm{Ga}$ & - & $<0,1$ & \\
$\mathrm{Perda}$ & - & $<0,1$ & \\
\hline
\end{tabular}

*Alumina Calcinada APC (Alcoa). aluminato de sódio ( $\mathrm{Na}_{1,71} \mathrm{Al}_{11} \mathrm{O}_{17}$, ICSD 01-084-0381) e sulfato de sódio $\left(\mathrm{Na}_{2} \mathrm{SO}_{4}\right.$, ICSD 01-075-0979).

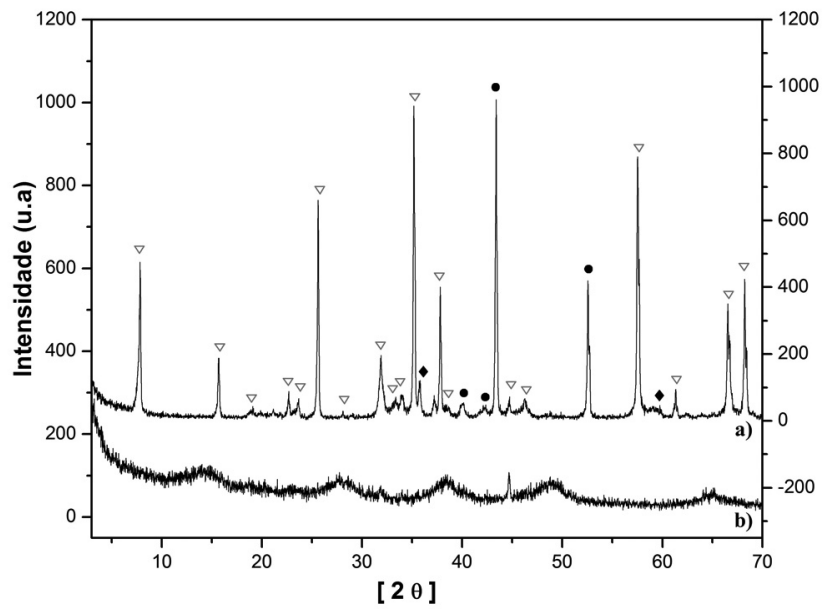

Figura 1. Difratograma de raios $X$ para o lodo (a) como fornecido, (b) calcinado a $1200^{\circ} \mathrm{C}(\nabla)$, alumina- $\alpha\left(\mathrm{Al}_{2} \mathrm{O}_{3}\right) ;(\bullet)$ aluminato de sódio $\left(\mathrm{Na}_{1,71} \mathrm{Al}_{11} \mathrm{O}_{17}\right)$; (•) sulfato de sódio $\left(\mathrm{Na}_{2} \mathrm{SO}_{4}\right)$

O tamanho de partículas é um fator que interfere no processo de sinterização, já que pode definir a densidade final dos materiais. ${ }^{11}$ Neste sentido, buscou-se reduzir o tamanho de partículas com o objetivo de diminuir a temperatura de sinterização. A moagem em moinho de bolas se estendeu por um período de até $144 \mathrm{~h}$. A partir de $96 \mathrm{~h}$, o tamanho médio de partículas $\left(d_{50}\right)$ foi de $1,75 \mu \mathrm{m}$ e permaneceu praticamente o mesmo após $120 \mathrm{~h}$ e 144 h (Tabela 2) indicando uma estabilização do processo.

Tabela 2. Distribuição do tamanho de partículas do lodo de anodização de alumínio antes e depois de moagem em moinho de bolas tipo industrial de cerâmica tradicional

\begin{tabular}{lccc}
\hline Lodo & $\begin{array}{c}\text { Diâmetro 10\% } \\
(\mu \mathrm{m})\end{array}$ & $\begin{array}{c}\text { Diâmetro 50\% } \\
(\mu \mathrm{m})\end{array}$ & $\begin{array}{c}\text { Diâmetro 90\% } \\
(\mu \mathrm{m})\end{array}$ \\
\hline Como fornecido & 1,3 & 7,07 & 20,24 \\
Calcinado & 1,51 & 18,4 & 53,80 \\
Calcinado e moído por & & & \\
$24 \mathrm{~h}$ & 0,60 & 2,95 & 14,35 \\
$48 \mathrm{~h}$ & 0,58 & 2,43 & 10,92 \\
$72 \mathrm{~h}$ & 0,52 & 2,11 & 7,42 \\
$96 \mathrm{~h}$ & 0,49 & 1,75 & 6,46 \\
$120 \mathrm{~h}$ & 0,45 & 1,76 & 5,27 \\
$144 \mathrm{~h}$ & 0,48 & 1,78 & 5,13 \\
\hline
\end{tabular}

Na moagem de alta energia, em moinho tipo planetário, o tamanho médio de partículas $\left(d_{50}\right)$ foi de 1,68 $\mu$ m após 25 min de moagem, estabilizando para tempos de moagem maiores. Pôde-se perceber um aumento discreto da área de superfície específica, isto é, de 4,21 $\mathrm{m}^{2} / \mathrm{g}$, antes do processo de moagem, para 5,08 $\mathrm{m}^{2} / \mathrm{g}$, após moagem em moinho de bolas por $144 \mathrm{~h}$ e para $5,23 \mathrm{~m}^{2} / \mathrm{g}$, após moagem em moinho planetário durante $25 \mathrm{~min}$. $\mathrm{O}$ aumento da área de superfície específica pode estar relacionado à forma irregular das partículas após moagem em moinho planetário, a qual é típica de processos de cominuição de alta energia. A Figura 2 mostra o comportamento térmico do lodo de anodização de alumínio após secagem.

Como pode ser observado a partir da análise da Figura 2, ocorreu uma perda de massa significativa entre 200 e $500{ }^{\circ} \mathrm{C}$, a qual 


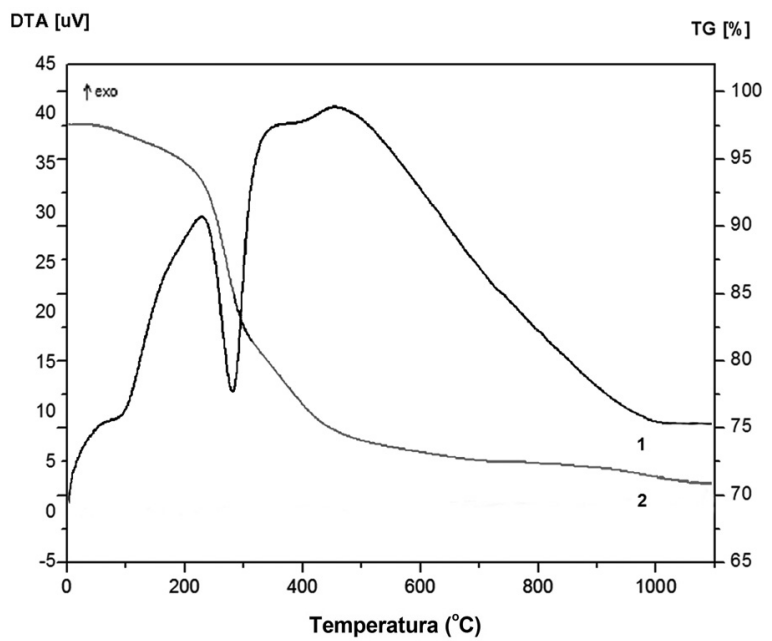

Figura 2. Análise térmica diferencial e termogravimétrica do lodo como fornecido. (1) ATD; (2) ATG

foi atribuída à decomposição de hidroxilas, confirmando assim os resultados de perda ao fogo. A curva de ATD mostrou um forte pico endotérmico a aproximadamente $286{ }^{\circ} \mathrm{C}$, que pode corresponder à decomposição de $\mathrm{Al}(\mathrm{OH})_{3}$. De acordo com a literatura, o $\mathrm{Al}(\mathrm{OH})_{3}$ se decompõe no intervalo de temperatura compreendido entre $200 \mathrm{e}$ $250{ }^{\circ} \mathrm{C} .{ }^{6,7} \mathrm{O}$ pequeno desvio de temperatura observado foi associado à presença de impurezas de anodização, como evidenciado por meio da composição química (Tabela 1). Aparentemente, os sulfatos de alumínio não estavam presentes em quantidades significativas, já que as suas decomposições não foram detectadas nas análises térmicas (ATD/ATG). O material calcinado, após moagem em moinho de alta energia, como evidenciado, apresentou tamanho médio de partícula de aproximadamente 1,68 $\mu \mathrm{m}$ com área de superfície específica de $5,23 \mathrm{~m}^{2} / \mathrm{g}$. Esse tamanho de partícula melhora a densidade a verde dos compactos de pós e, consequentemente, aumenta a reatividade das partículas durante sinterização, resultando em materiais à base de alumina com propriedades adequadas para uma dada aplicação. De fato, a curva de retração térmica linear, obtida por meio de dilatometria ótica (Figura 3), mostra que o processo de densificação se inicia a aproximadamente $1300{ }^{\circ} \mathrm{C}$, praticamente terminando a $1450{ }^{\circ} \mathrm{C}$, quando a taxa de densificação tende a zero.

Análises térmicas (ATD/TG) subsequentes mostraram que a esponja de PU é decomposta a $550{ }^{\circ} \mathrm{C}$. A Figura 4 mostra um

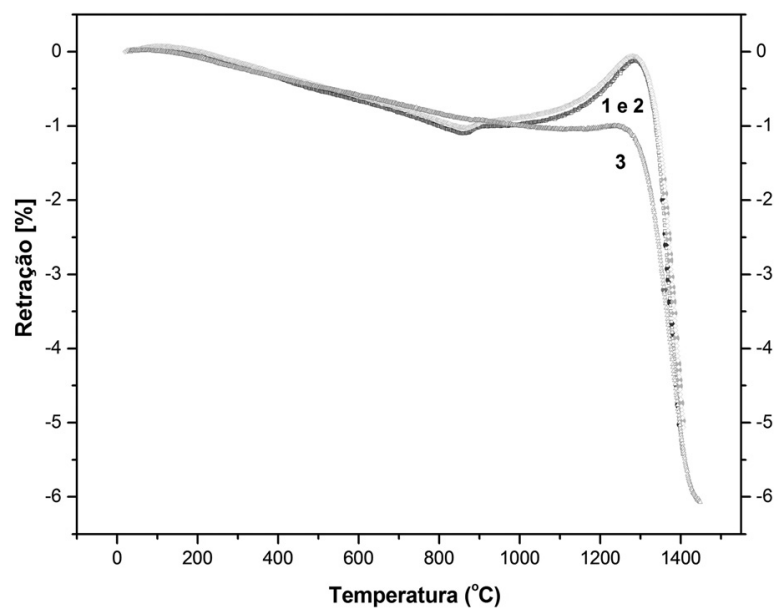

Figura 3. Curva dilatométrica dos lodos: (1) lodo calcinado; (2) lodo calcinado e moído em moinho de bolas por 144 h e (3) lodo calcinado e moído em moinho planetário por $25 \mathrm{~min}$ comportamento reológico típico de suspensões de alumina $\left(\mathrm{Al}_{2} \mathrm{O}_{3}\right)$. Medidas reológicas, tais como as de tensão de cisalhamento em função da taxa de cisalhamento, podem fornecer informações para a escolha de um sistema de composição particular (solvente, ligante, dispersante) como critério para a seleção da melhor condição de processamento.

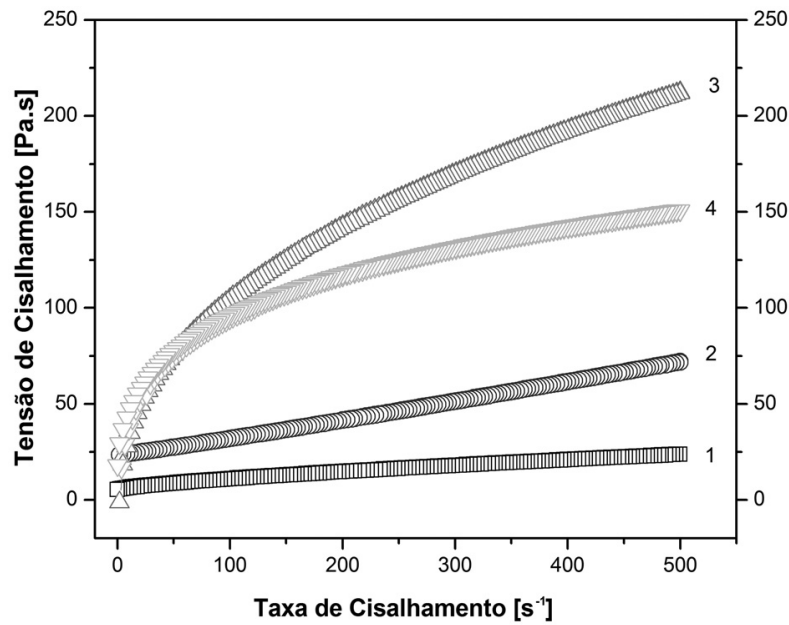

Figura 4. Curva da tensão de cisalhamento por taxa de cisalhamento em função da adição de sólidos. (1) $50 \%$ sólidos; (2) $54 \%$ sólidos; (3) $58 \%$ sólidos e (4) $61 \%$ sólidos

Como pode ser observado, a suspensão apresenta um comportamento pseudoplástico, isto é, a viscosidade aparente diminui com o aumento da taxa de cisalhamento. Tal comportamento pode ser relacionado à ruptura de aglomerados na suspensão, os quais foram quebrados quando submetidos ao viscosímetro (cisalhamento). De acordo com as medidas reológicas e os testes de impregnação, concluiu-se que a concentração otimizada (em massa) para a impregnação da esponja de PU corresponde a $54 \%$ de alumina calcinada e $46 \%$ de água destilada com adições de $6 \%$ de bentonita e $1 \%$ de ácido cítrico.

Com relação à densificação dos filamentos ou arestas de compactos de suspensões preparadas com pós moídos a úmido e a seco (moinho planetário) e sinterizados a $1600{ }^{\circ} \mathrm{C} / 2 \mathrm{~h}$, as medidas de densidade e, portanto, a porosidade e retração linear calculadas indicaram valores de 15 e 14,3\%, respectivamente, para os compactos de pós moídos a úmido por 144 h. Para a moagem a seco, em moinho planetário, por $25 \mathrm{~min}$, no entanto, a porosidade foi de $1 \%$ e a retração linear de 26,5\%. Em função desse último resultado, as espumas preparadas e testadas foram produzidas com pós moídos a seco, já que apresentaram maior densificação nas arestas indicando, assim, uma melhor resistência mecânica das estruturas celulares. De fato, ensaios de resistência à compressão de compactos de pós moídos a úmido e a seco e sinterizados a $1600{ }^{\circ} \mathrm{C} / 2 \mathrm{~h}$ indicaram valores de 56 e $74 \mathrm{MPa}$, respectivamente. Assim, as espumas cerâmicas preparadas à base de lodo calcinado e moído por $25 \mathrm{~min}$, em moinho planetário, apresentaram porosidade de $70,4 \%$ e retração linear de $20,9 \%$. O percentual efetivo de sólidos retido na espuma (\% ES) foi de $26,6 \%$ e sem os canais (\%SSC) foi de $23,6 \%$.

A Figura 5 mostra micrografias da espuma de PU e de espumas sinterizadas. Como é possível observar (Figuras 5a e 5b), houve uma boa reprodução (réplica) da estrutura celular da espuma de PU, com uma diminuição de porosidade de $26,6 \%$, que está relacionada à retração linear resultante $(\sim 21 \%)$. A micrografia da Figura $5 \mathrm{c}$, com maior aumento, mostra a estrutura celular de uma amostra sinterizada, evidenciando a estrutura de filamentos, aparentemente mais compacta e de baixa porosidade, com a presença de microtrincas originadas durante a etapa de processamento. 

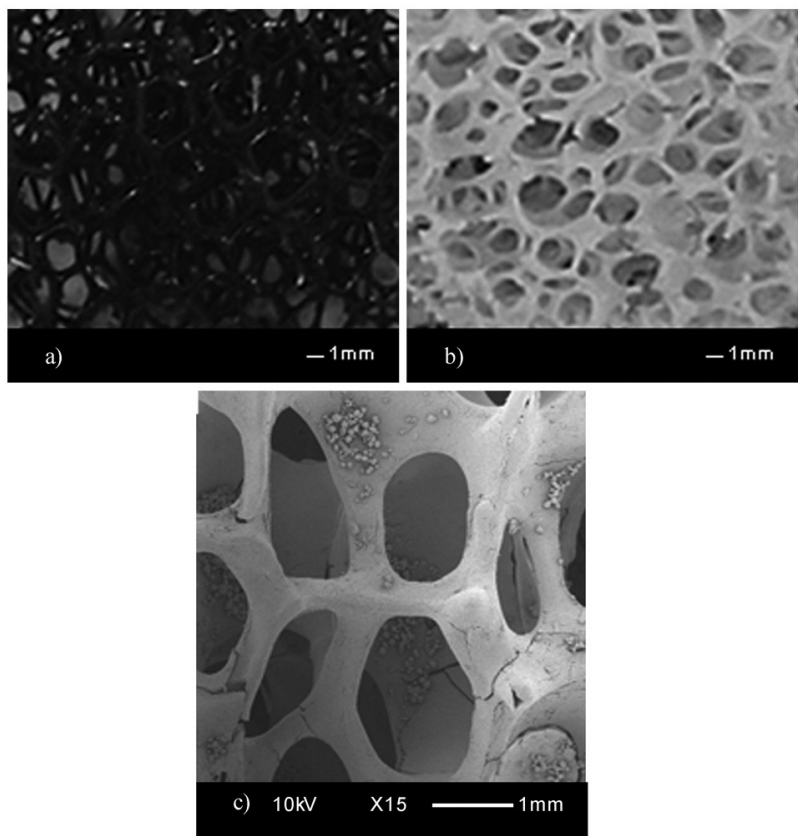

Figura 5. Micrografias (MEV): (a) espuma de PU utilizada; (b,c) espumas cerâmicas sinterizadas a $1600^{\circ} \mathrm{C} / 2 \mathrm{~h}$

A Figura 6 mostra a distribuição normal de Weibull referente às amostras das espumas sinterizadas. Com base nos dados da Figura 6 , a tensão característica $\left(\sigma_{0}\right)$, estimada para $63,2 \%$ das amostras ensaiadas, foi de 2,40 MPa (módulo de Weibull de 5,15).

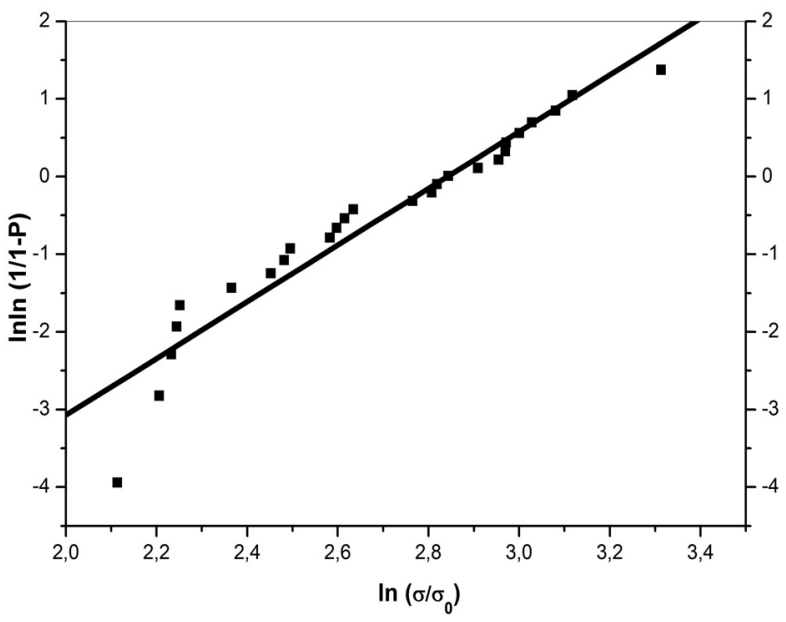

Figura 6. Distribuição normal de Weibull para as espumas produzidas

Através do choque térmico, pode ocorrer nos materiais/componentes testados uma diminuição progressiva ou mesmo abrupta da resistência mecânica, devido à formação de trincas ou à propagação de trincas pré-existentes, que ocorrem como resultado das tensões geradas em consequência das altas taxas de resfriamento, como foi evidenciado na micrografia da Figura $5 \mathrm{c}$. Desse modo, pode-se supor que, embora o gradiente de temperatura se estabeleça através do filtro como um todo, o dano estrutural causado no filtro está relacionado à tensão térmica que atua nos filamentos individualmente. ${ }^{14}$ No caso das espumas sinterizadas, o ensaio de choque térmico foi utilizado para determinar a capacidade das peças de suportarem a diferença de temperatura do alumínio fundido, no momento do vazamento, sendo necessário, portanto, um ciclo térmico. A temperatura de trabalho para filtros de alumina fica em torno de 800 a $1000^{\circ} \mathrm{C}$. Assim, as espumas sinterizadas foram esfriadas em água, a temperatura ambiente $\left(24^{\circ} \mathrm{C}\right)$, a partir de 800,900 e $1000^{\circ} \mathrm{C}$ e não apresentaram trincas ou defeitos críticos visíveis. Após os ensaios de resistência ao choque térmico, as amostras foram submetidas a ensaios mecânicos, sendo a resistência mecânica à compressão média medida de 2,07 MPa.

A vazão mássica é utilizada na indústria como parâmetro para determinar a capacidade de filtragem de filtros. O tempo de escoamento de ligas fundidas na temperatura de operação é semelhante ao da água à temperatura ambiente. Assim, faz-se essa medida passando-se água através do filtro. As espumas sinterizadas, produzidas a partir da espuma de poliuretano, apresentaram vazão mássica $\left(Q_{m}\right)$ de 1,7 $\mathrm{kg} / \mathrm{s}$, a qual é um valor próximo daquele reportado na literatura para filtros comerciais $(1,8 \mathrm{~kg} / \mathrm{s}) .^{15}$

\section{CONCLUSÕES}

$\mathrm{O}$ teor de alumina $\left(\mathrm{Al}_{2} \mathrm{O}_{3}\right)$ aumentou significativamente após processo de calcinação passando de 55,5\%, como fornecido, para $87,5 \%$ após calcinação a $1200{ }^{\circ} \mathrm{C}$. A composição química média do lodo calcinado mostrou pequenas quantidades de outros óxidos como resultado de contaminação e dos agentes químicos utilizados no tratamento das águas de lavagem.

A difratometria de raios $\mathrm{X}$ indicou que o lodo como fornecido é praticamente amorfo, pois nenhuma fase cristalina foi detectada. No estado calcinado, foi detectada a presença de alumina- $\alpha$, aluminato e sulfato de sódio.

A moagem feita em moinho de bolas, tipo industrial e comumente utilizado na indústria de cerâmica tradicional, estendeu-se por $144 \mathrm{~h}$, resultando em partículas com tamanho $\left(\mathrm{d}_{50}\right)$ de $1,78 \mu \mathrm{m}$. Na moagem de alta energia em moinho tipo planetário, o tamanho de partículas $\left(\mathrm{d}_{50}\right)$ resultante foi de $1,68 \mu \mathrm{m}$ após 25 min de moagem. A maior eficiência de moagem no moinho planetário é fundamental para a obtenção de materiais mais densos (filamentos mais densos) e resistentes mecanicamente.

Através das curvas de retração linear, para os lodos no estado calcinado e moídos, pode-se observar que o processo de densificação teve início a aproximadamente $1300{ }^{\circ} \mathrm{C}$ sendo que a partir de 1450 ${ }^{\circ} \mathrm{C}$ a taxa de densificação tende a diminuir.

No estudo reológico, observou-se que as suspensões apresentaram comportamento pseudoplástico, isto é, a viscosidade aparente diminui com o aumento da taxa de cisalhamento. A composição otimizada apresentou limite de concentração de sólidos adequado, correspondente a $54 \%$ de sólidos.

Os compactos preparados com pós moídos a seco em moinho planetário e sinterizados a $1600{ }^{\circ} \mathrm{C} / 2 \mathrm{~h}$, apresentaram porosidade (ع) de $1 \%$ e retração térmica linear (RL) de $26,5 \%$ e as respectivas espumas sinterizadas apresentaram valores de porosidade $(\varepsilon)$ de $70,4 \%$ e retração térmica linear (RL) de $20,9 \%$.

A tensão característica $\left(\sigma_{0}\right)$ estimada, para $63,2 \%$ das amostras ensaiadas, foi de 2,40 MPa (módulo de Weibull de 5,15).

As espumas sinterizadas esfriadas em água, a temperatura ambiente $\left(24^{\circ} \mathrm{C}\right)$, não apresentaram trincas ou defeitos críticos visíveis, de modo que após ensaios mecânicos a resistência à compressão média foi de 2,07 MPa.

As espumas sinterizadas, produzidas a partir da espuma de poliuretano, apresentaram vazão mássica, $\left(Q_{m}\right)$ de $1,7 \mathrm{~kg} / \mathrm{s}$, que é um valor próximo daquele reportado na literatura para filtros comerciais $(1,8 \mathrm{~kg} / \mathrm{s})$.

\section{AGRADECIMENTOS}

\section{À CAPES e ao CNPq.}




\section{REFERÊNCIAS}

1. ISO - International Organization for Standardization; Environmental management - Life cycle assessment: principles and framework - ISO 14.040, ISO: Genebra, 1997.

2. Oliveira, A. P. N.; Gomes, V.; Hotza, D.; Montedo, O. R. K.; Piccoli, R.; Pereira, F. R.; Interceram 2003, 52, 1.

3. Lawrence, J. D.; Graham's Electroplating Engineering Handbook, $4^{\text {th }}$ ed.; Chapman \& Hall: New York, 1996.

4. Pereira, D. A.; Couto, D. M.; Labrincha, J. A.; Ceram. Forum Int. 2000, $77,7$.

5. Casagrande, M. C.; Sartor, M. N.; Gomes, V.; Della, V. P.; Hotza, D.; Oliveira, A. P. N.; Cerâm. Ind. 2008, 13, 1.

6. Ribeiro, M. J.; Tulyaganov, D. U.; Ferreira, J. M.; Labrincha, J. A.; Ceram. Int. 2002, 28, 3.

7. Ferreira, J. M.; Olhero, S. M.; J. Eur. Ceram. Soc. 2002, 22, 13.

8. Sartor, M. N.; Correia, S. L.; Hotza, D.; Segadães, A. M.; Labrincha, J. A.; Oliveira, A. P. N.; Amer. Ceram. Soc. Bull. 2008, 87, 5.
9. Gomes, V.; Tese de Doutorado, Universidade Federal de Santa Catarina, Brasil, 2005.

10. Raupp-Pereira, F.; Tese de Doutorado, Universidade de Aveiro, Portugal, 2006.

11. Scheffler, M.; Colombo, P.; Cellular Ceramics: Structure, Manufacturing, Properties and Applications, Wiley-VCH: New York, 2005.

12. Silveira, C. B.; Escobar, J. A.; Quintero, M. W.; Sousa, E.; Moraes, E. G.; Oliveira, A. P. N.; Rambo, C. R.; Hotza, D.; Quim. Nova 2007, 30, 1104.

13. ABNT - Associação Brasileira de Normas Técnicas; Materiais Refratários - Determinação da resistência ao choque térmico com resfriamento em água - NBR 13202, ABNT: Rio de Janeiro, 1997.

14. Salvini, V. R.; Pupim, A. M.; Innocentini, M. D. M.; Pandolfelli, V. C.; Cerâmica 2001, 47, 301.

15. Brown, G. R.; Foseco Ferrous Foundryman's Handbook, Butterworth \& Heinemann: Oxford, 2000 